\title{
OS SABERES DOCENTES DOS PROFESSORES DA REDE E- TEC BRASIL: UM ESTUDO DE CASO NO SUL DO PAÍS
}

\section{TEACHING KNOWLEDGE OF TEACHERS OF THE E-TEC BRASIL NETWORK: A CASE STUDY IN THE SOUTH OF THE COUNTRY}

\author{
Roberta Pasqualli ${ }^{(1)}$; Marie Jane Soares Carvalho( ${ }^{(2)}$ \\ (1) Instituto Federal de Educação, Ciência e Tecnologia de Santa \\ Catarina (Brasil);(2) Universidade Federal do Rio Grande do Sul \\ (Brasil)
}
E-mail: roberta.pasqualli@ifsc.edu.br( ${ }^{(1)}$; mariejsc@gmail.com ${ }^{(2)}$
ID. ORCID: https://orcid.org/0000-0001-8293-033X(1); https://orcid.org/0000- 0003-1746-2044(2)

Recebido: 04/08/2021

Aceite: 10/09/2021

Publicado: 16/09/2021

\section{RESUMO}

O texto contribui com as discussões sobre a formação e profissão docente no âmbito da Educação Profissional e Tecnológica (EPT) por meio da Educação a Distância (EAD), apresentando uma análise sobre os saberes fundamentais à docência nesta modalidade de educação. Como aportes teóricos, baseou-se em Alarcão (1998), Bicudo (1999), Charlot (2018), Kuenzer (2008), Tardif (2002) entre outros. Metodologicamente, trata de pesquisa qualitativa, documental e de campo com enfoque na investigação fenomenológica. Estruturou-se por meio das análises ideográfica e nomotética oriundas das falas de gestores, professores e tutores da Rede E-Tec Brasil no Instituto Federal Farroupilha (IFFAR). Os resultados indicam como saberes fundamentais para a atividade docente na EPT: os saberes da profissionalização docente e, entre eles, destacam-se os saberes dos contextos dos estudantes, da linguagem, da utilização dos aparatos tecnológicos, da generosidade, o mundo do trabalho e os saberes da formação humana não utilitarista.

Pasqualli, Roberta; Carvalho, Marie Jane Soares (2021). Os saberes docentes dos professores da Rede E-TEC Brasil: um estudo de caso no sul do país. DEDiCA. REVISTA DE EDUCAÇÃO E HUMANIDADES, N. 19 , 2021, 333-352. ISSN: 2182-018X. DOI: http://doi.org/10.30827/dreh.vi19.21951 


\section{Palavras-chave:}

Educação a Distância; Educação Profissional e Tecnológica; saberes docentes

\section{ABSTRACT}

The text contributes to the discussions on teacher education and profession within the scope of Professional and Technological Education (EFA) through Distance Education (EAD), presenting an analysis of the fundamental knowledge to teaching in this education modality. Its theoretical contributions are based on Alarcão (1998), Bicudo (1999), Charlot (2018), Kuenzer (2008), Tardif (2002), among others. Methodologically, it is a qualitative, documentary and field research focused on phenomenological research. It was structured through ideographic and nomothetic analysis from the speeches of managers, teachers, and tutors of the E-Tec Brazil Network at the Federal Institute Farroupilha (IFFAR). The results indicate as fundamental knowledge for the teaching activity in EFA: the teaching professional knowledge of which stands out the knowledge of the students' contexts, language, use of technological devices, generosity, the world of work, and the knowledge of non-utilitarian human formation.

\section{Keywords}

Distance Education; Professional and Technological Education; teaching knowledge

\section{Introdução}

Este texto apresenta uma discussão sobre a problemática dos saberes docentes mobilizados pelos professores dos cursos de Educação Profissional e Tecnológica (EPT), ofertados na modalidade de Educação a Distância (EAD), pela Rede E-Tec Brasil, no Instituto Federal de Educação, Ciência e Tecnologia Farroupilha (IFFAR).

Como premissa, compreende-se que a investigação acerca dos saberes docentes fundamentais aos professores da EPT a distância, indica um avanço para as discussões, até então pouco evidenciadas nas pesquisas em educação brasileira. Denota, também, reafirmar a necessidade de se discutirem ações de capacitação específica para cada nível e modalidade de ensino nos

Pasqualli, Roberta; Carvalho, Marie Jane Soares (2021). Os saberes docentes dos professores da Rede E-TEC Brasil: um estudo de caso no sul do país. DEDICA. REVISTA DE EDUCAÇÃO E HUMANIDADES, N. 19, 2021, 333-352. ISSN: http://doi.org/10.30827/dreh.vi19.21951

2182-018X.

DOI: 
cursos de profissionalização docente. Significa, no espaço de contradições que são os Institutos Federais de Educação Científica e Tecnologia (IFs),observar que a prática docente não é apenas um objeto de saber para 'os da educação'. Significa que "o que um professor sabe depende também daquilo que ele não sabe, daquilo que se supõe que ele não saiba, daquilo que os outros sabem em seu lugar e em seu nome, dos saberes que os outros lhe opõem ou Ihe atribuem" (Tardif, 2002, p. 13).

Como local para a realização da pesquisa, escolheu-se o IFFAR, que faz parte de um grupo de "instituições de educação superior, básica e profissional, pluricurriculares e multicampi, especializados na oferta de educação profissional e tecnológica nas diferentes modalidades de ensino, com base na conjugação de conhecimentos técnicos e tecnológicos com as suas práticas pedagógicas (Brasil, 2008). Os IFs são conhecidos por atuar em todos os níveis e modalidades de educação profissional, tendo como foco a oferta de uma estrutura verticalizada de formação humana e profissional, não desejando ser apenas um amontoado de cursos sem ligações entre si. Destaca-se, em suas ações, a promoção da justiça social, da equidade e do desenvolvimento sustentável, tendo em vista soluções técnicas e a geração de novas tecnologias, respondendo às demandas a eles apresentados de forma ágil e eficaz, enfatizando a formação profissional, a difusão de conhecimentos científicos e o suporte aos arranjos produtivos locais.

Objetivando a discussão acerca dos saberes docentes mobilizados pelos professores dos cursos de EPT, ofertados na modalidade de EAD, pela Rede E-Tec Brasil, destaca-se o Artigo 7을 incisos I, II e VI, da Lei no 1.892/2008, pois afirmam ser finalidades e características dos IFs: "ministrar educação profissional técnica de nível médio, prioritariamente na forma de cursos integrados, para os concluintes do ensino fundamental e para o público da educação de jovens e adultos"; "ministrar cursos de formação inicial e continuada de trabalhadores, objetivando a capacitação, o aperfeiçoamento, a especialização e a atualização de profissionais, em todos os níveis de escolaridade, nas áreas da educação profissional e tecnológica" e "ministrar em nível de educação superior [...]" (Brasil, 2008).

Nesta direção, também cabe um breve olhar sobre a

Pasqualli, Roberta; Carvalho, Marie Jane Soares (2021). Os saberes docentes dos professores da Rede E-TEC Brasil: um estudo de caso no sul do país. DEDiCA. REVISTA DE EDUCAÇÃO E HUMANIDADES, N.19, 2021, 333-352. ISSN: 2182-018X. DOI: http://doi.org/10.30827/dreh.vi19.21951 
orientação pedagógica dos IFs, apontada por Pacheco (2010), como a possibilidade de "[...] recusar o conhecimento exclusivamente enciclopédico, assentando-se no pensamento analítico, buscando uma formação profissional mais abrangente e flexível, com menos ênfase na formação para ofícios e mais na compreensão do mundo do trabalho e em uma participação qualitativamente superior neste. Um profissionalizar-se mais amplo, que abra infinitas possibilidades de reinventar-se no mundo e para o mundo, princípios estes válidos inclusive para as engenharias e licenciaturas" (Pacheco, 2010, p. 14).

Para dar conta das demandas oriundas de seus objetivos, finalidades e de sua orientação pedagógica, os IFs vem oferecendo, por meio da Rede E-Tec Brasil, cursos de formação profissional, inicial e continuada, na modalidade de EAD. O Decreto $\mathrm{n}^{\circ}$ 7.589/2011 afirma que a Rede E-Tec Brasil é uma das ações que integram o Programa Nacional de Acesso ao Ensino Técnico e Emprego (PRONATEC) e tem como finalidade oferecer, na modalidade de educação a distância, por meio da proposta de verticalização de ensino apresentada pela Rede de Educação Profissional e Tecnológica (EPT) cursos de formação inicial e continuada de trabalhadores, cursos de ensino técnico nas modalidades integrado ao ensino médio, concomitante e subsequente ao ensino médio, cursos superiores de tecnologia e cursos de pós-graduação lato e stricto sensu.

Acerca deste decreto dá-se atenção ao Artigo $3^{\circ}$ que, ao apresentar seus objetivos, destaca, entre outros, "II - expandir e democratizar a oferta da educação profissional e tecnológica, especialmente para o interior do País e para a periferia das áreas metropolitanas; III - permitir a capacitação profissional inicial e continuada, preferencialmente para os estudantes matriculados e para os egressos do ensino médio, bem como para a educação de jovens e adultos; IV - contribuir para o ingresso, permanência e conclusão do ensino médio por jovens e adultos; $V$ - permitir às instituições públicas de ensino o desenvolvimento de projetos de pesquisa e de metodologias educacionais em educação a distância na área de formação inicial e continuada de docentes para a educação profissional e tecnológica" (Brasil, 2011).

Pasqualli, Roberta; Carvalho, Marie Jane Soares (2021). Os saberes docentes dos professores da Rede E-TEC Brasil: um estudo de caso no sul do país. DEDiCA. REVISTA DE EDUCAÇÃO E HUMANIDADES, N.19, 2021, 333-352. ISSN: 2182-018X. DOI: http://doi.org/10.30827/dreh.vi19.21951 
Sendo assim, observa-se a importância de que se elaborem Projetos Pedagógicos de Curso (PPC) voltados para a formação do homem e do profissional, e que estes projetos se materializem por meio de práticas pedagógicas que auxiliem no desafio da construção do conhecimento científico, assegurando sua aplicabilidade no mundo do trabalho. Entende-se que esta transformação não seja possível sem que haja uma ruptura com os moldes da educação tradicional e, é neste sentido que Cunha (2005), apresenta a ideia de que é necessário romper com o paradigma existente e que, esse rompimento, deve transformar inquietude em energia emancipatória.

Com o olhar voltado à geração da energia emancipatória apontada por Cunha (2005), discutem-se os saberes docentes fundamentais para o exercício da docência na EPT a distância brasileira. Que saberes são estes? Eles se diferem dos saberes empregados na educação presencial? São diferentes dos saberes mobilizados na educação propedêutica ou na educação superior?

No âmbito da EAD, cabe a preocupação com sua qualidade, visto que a modalidade, apesar de se apresentar como uma possibilidade de democratização da educação brasileira, ainda enfrenta preconceitos e busca encontrar um caminho que a diferencie da educação presencial (novos saberes, novos fazeres).

É nesse contexto que este texto se inscreve: concebido como uma reflexão, uma revisão e um processo de investigação articulado à realidade atual da educação brasileira. Partiu-se do pressuposto de que a produção científica se deve caracterizar como um espaço que busca qualificar a ação docente na EPT, especialmente para a formação de professores na modalidade de EAD, situando-a como possibilidade de superação da educação tradicional, presente em boa parte das aulas (e na própria EAD), criando, de fato, rupturas com o fazer existente.

\section{Método}

Tendo como foco a interrogação 'Que saberes docentes são mobilizados pelos professores dos cursos de EPT, ofertados na modalidade de EAD pela Rede E-Tec Brasil?', este artigo apresenta

Pasqualli, Roberta; Carvalho, Marie Jane Soares (2021). Os saberes docentes dos professores da Rede E-TEC Brasil: um estudo de caso no sul do país. DEDICA. REVISTA DE EDUCAÇÃO E HUMANIDADES, N. 19, 2021, 333-352. ISSN:

http://doi.org/10.30827/dreh.vi19.21951

2182-018X.

DOI: 
resultados de uma investigação que buscou compreender o sentido dos saberes mobilizados pelos professores da EPT e como tais saberes orientam as ações e orientam seu trabalho. O locus da pesquisa foi o IFFAR, localizado no estado do Rio Grande do Sul, Brasil.

Até fevereiro de 2020, de acordo com as informações do sítio institucional, o IFFAR ofertava 3 cursos técnicos subsequentes na modalidade de EAD nas áreas de administração e ciências agrárias oferecidos em 7 polos. Destaca-se, entretanto, que em 2016, quando foi realizada a coleta de dados desta pesquisa, 0 IFFAR oferecia 17 cursos técnicos subsequentes na modalidade de EAD em 37 polos de EAD. A redução de ofertas de cursos, turmas e polos não é objeto deste estudo, mas configura dado interessante para pesquisas futuras.

Os participantes investigados foram 11 gestores de EAD (G), 9 professores formadores (PF) e 20 tutores (T), totalizando 40 sujeitos e seguindo os aspectos éticos da pesquisa, incluindo aprovação em comitê de ética em pesquisa (CEP).

Ao procurar possibilidades que abarcassem 0 desenvolvimento da pesquisa realizada, optou-se pelas abordagens qualitativa, documental e de campo, com enfoque fenomenológico. Uma vez que a primeira está relacionada "à capacidade de possibilitar a compreensão do significado e a descrição densa dos fenômenos estudados em seu contexto e não a sua expressividade numérica" (Goldenberg, 1997, p. 50). Enquanto que a segunda "não traz consigo a imposição de uma verdade teórica ou ideológica preestabelecida, mas trabalha com o real vivido, buscando a compreensão disso que somos e que fazemos - cada um de nós e todos em conjunto" (Bicudo, 1999, p. 13).

A pesquisa foi realizada em dois momentos e constitui-se por meio da análise ideográfica e nomotética ${ }^{1}$ dos dados. Buscouse identificar, direta e indiretamente, elementos que pudessem indicar os saberes docentes no contexto dos cursos de EPT a distância nos Institutos Federais de Educação. No que se refere à análise ideográfica, os resultados foram produzidos a partir das falas de professores formadores, tutores e gestores, dos cursos técnicos de nível médio em Informática, Vendas, Meio Ambiente,

Pasqualli, Roberta; Carvalho, Marie Jane Soares (2021). Os saberes docentes dos professores da Rede E-TEC Brasil: um estudo de caso no sul do país. DEDiCA. REVISTA DE EDUCAÇÃO E HUMANIDADES, N․19, 2021, 333-352. ISSN: 2182-018X. DOI: http://doi.org/10.30827/dreh.vi19.21951 
Agroindústria, Manutenção e Suporte em Informática, Agricultura, Multimeios Didáticos, Administração, Redes de Computadores e Secretariado, oferecidos por meio da Rede E-Tec, no IFFAR.

Os depoimentos foram individuais, sem a interferência de terceiros, baseados em questionamentos previamente elaborados. Entretanto, elementos não existentes nos questionamentos diretos foram apresentados sem que houvesse interferência do pesquisador. Foi o momento de se olhar as frestas, aquilo que se anuncia como saber sem necessariamente perguntar. $\mathrm{Na}$ análise nomotética, as falas dos participantes foram encaminhadas em direção às generalidades, ou seja, de características básicas compreendidas nas formas de manifestação do fenômeno, passíveis de interpretação.

É este movimento da pesquisa e seus desdobramentos analíticos que serão explorados a seguir.

\section{Resultados}

Das falas dos participantes investigados tomadas, refletidas e esclarecidas, foi possível seguir para uma síntese de compreensão do fenômeno investigado, por meio das análises ideográfica e nomotética.

$\mathrm{Na}$ análise ideográfica, as falas dos participantes da pesquisa foram transcritas na íntegra. Ao ouvir as falas durante a transcrição, pôde-se perceber as temáticas que remetem à ideia central da pesquisa, e essas ideias centrais foram nomeadas como episódios ideográficos. Ao todo, foram apontados cinco episódios ideográficos, descritos a seguir: (a) saberes fundamentais para os professores que atuam nos cursos de educação profissional e tecnológica na modalidade de EAD; (b) saberes didáticopedagógicos; (c) concepção de educação e trabalho interfere na prática docente; (d) projeto pedagógico dos cursos de EAD; e (e) práticas inovadoras na EAD.

Pasqualli, Roberta; Carvalho, Marie Jane Soares (2021). Os saberes docentes dos professores da Rede E-TEC Brasil: um estudo de caso no sul do país. DEDICA. REVISTA DE EDUCAÇÃO E HUMANIDADES, N. 19, 2021, 333-352. ISSN:

2182-018X.

DOI: http://doi.org/10.30827/dreh.vi19.21951 


\section{Quadro 1 - Episódios Ideográficos}

\begin{tabular}{|c|c|}
\hline Fala Significativa & $\begin{array}{l}\text { Episódio } \\
\text { Ideográfico }\end{array}$ \\
\hline $\begin{array}{l}\text { Em primeiro gostar do que faz, ser responsável pelo } \\
\text { seus atos como educador e ter a capacidade estar } \\
\text { sempre atualizado com o aprendizado, pois todos nós } \\
\text { estamos em uma caminhada de saberes (PF1). } \\
\text { Acredito que a maior importância é você estar } \\
\text { aprendendo sempre, para ter uma ótima base. (PF2). } \\
\text { No exercício da docência acho importante a disciplina, } \\
\text { o conhecimento e a maneira de se expressar perante a } \\
\text { uma turma, pois essas três características devem } \\
\text { sempre atuar em conjunto para a interação entre aluno } \\
\text { e professor (PF3). } \\
\text { Conhecimento, em primeiro lugar. O professor deve } \\
\text { dominar o assunto a ser trabalhado com os alunos. } \\
\text { Depois, uma disposição para transmitir } \\
\text { conhecimentos da maneira mais clara possível (PF5, } \\
\text { G1). } \\
\text { Conhecer a realidade do aluno para o qual preparamos } \\
\text { a aula, qual abordagem é mais especifica para } \\
\text { determinado grupo de pessoas (adolescentes, jovens, } \\
\text { adultos, idosos) terá maior sucesso, tendo em vista que } \\
\text { o processo ensino-aprendizagem é dinâmico (PF8, T8). } \\
\text { Conhecer a realidade do aluno para o qual preparamos } \\
\text { a aula, qual abordagem é mais especifica para } \\
\text { determinado grupo de pessoas (adolescentes, jovens, } \\
\text { adultos, idosos) terá maior sucesso, tendo em vista que } \\
\text { o processo ensino-aprendizagem é dinâmico (PF9). }\end{array}$ & $\begin{array}{l}\text { Saberes } \\
\text { fundamentais } \\
\text { para os } \\
\text { professores } \\
\text { que atuam nos } \\
\text { cursos de } \\
\text { educação } \\
\text { profissional e } \\
\text { tecnológica na } \\
\text { modalidade de } \\
\text { EAD }\end{array}$ \\
\hline $\begin{array}{l}\text { Para mim todo o professor tem um seu conhecimento } \\
\text { adquirido em sua graduação, os professores das áreas } \\
\text { técnica tem muita dificuldade em interagir com as nova } \\
\text { tecnologias, exemplos nossos. [..] todos os } \\
\text { professores que estão atuando no EAD devem ter } \\
\text { muitas capacitações pontuais para o uso corre dos } \\
\text { recurso e ferramentas do Moodle, pois senão ele irão } \\
\text { reproduzir o ensino presencial no EAD (PF5, G1). } \\
\text { Existem saberes que auxiliam os professores na }\end{array}$ & $\begin{array}{l}\text { Saberes } \\
\text { didático- } \\
\text { pedagógicos }\end{array}$ \\
\hline
\end{tabular}

Pasqualli, Roberta; Carvalho, Marie Jane Soares (2021). Os saberes docentes dos professores da Rede E-TEC Brasil: um estudo de caso no sul do país. DEDiCA. REVISTA DE EDUCAÇÃO E HUMANIDADES, N․19, 2021, 333-352. ISSN: 2182-018X. DOI: http://doi.org/10.30827/dreh.vi19.21951 


\begin{tabular}{|c|c|}
\hline $\begin{array}{l}\text { elaboração da proposta metodológica da disciplina sim, } \\
\text { como por exemplo saber a que público se destina, se } \\
\text { essas pessoas possuem intimidade com o computador, } \\
\text { a internet e o AVA2. Elaborar quanto a estética da } \\
\text { disciplina de forma clara, organizada e com as } \\
\text { informações importantes em destaque. Ser objetivo, ter } \\
\text { linguagem acessível a fim de que o aluno entenda o } \\
\text { que está sendo solicitado e cumpra o que foi proposto } \\
\text { (PF6). } \\
\text { No sentido mais amplo possível do termo, sim. Como } \\
\text { "montar" um plano de ensino, formas de avaliação } \\
\text { individuais e em grupo foram importantes (PF7). } \\
\text { Compreender como o conhecimento é formado, quais } \\
\text { são as melhores metodologias, os métodos de } \\
\text { avaliação que são realmente eficientes... tudo isso foi } \\
\text { muito importante, e continua sendo. Precisamos } \\
\text { sempre rever e adequar nossa prática pedagógica } \\
\text { (T11). }\end{array}$ & \\
\hline $\begin{array}{l}\text { Primeiro, não concebo uma atividade intelectual como } \\
\text { trabalho. O trabalho está destinado ao labor. Claro que } \\
\text { o trabalho é uma atividade fundamental da condição } \\
\text { humana, como a fabricação e a ação. Essa concepção, } \\
\text { que não é minha, mas de Arendt3, interfere não só na } \\
\text { minha visão de educação, como de mundo. Assim, não } \\
\text { vinculo professores como parte dos trabalhadores em } \\
\text { educação. Nem utilizo termos como "chão de escola", } \\
\text { etc. (PF5, G1). } \\
\text { Ser professor ou tutor da e-Tec me proporciona um } \\
\text { olhar mais amplo em relação ao conhecimento e a } \\
\text { certeza que todos nos devemos estar em busca de } \\
\text { oportunidade educacionais e proporcionar saberes as } \\
\text { pessoas distantes de nós (T14). } \\
\text { O tutor à distância está no apoio do professor e com } \\
\text { ele possui maior contato, já o tutor presencial interage } \\
\text { mais com o aluno. Vejo meu trabalho como o elo de } \\
\text { ligação entre esses dois extremos. O aluno precisa de } \\
\text { incentivo, da confiança em saber que está sendo bem } \\
\text { acompanhado mesmo que a distância, seja na troca de } \\
\text { emails, no retorno de um trabalho, ou até mesmo por } \\
\text { contato telefônico em alguns casos. Caso não haja }\end{array}$ & $\begin{array}{l}\text { Concepção de } \\
\text { educação e } \\
\text { trabalho } \\
\text { interfere na } \\
\text { prática } \\
\text { docente }\end{array}$ \\
\hline
\end{tabular}

Pasqualli, Roberta; Carvalho, Marie Jane Soares (2021). Os saberes docentes dos professores da Rede E-TEC Brasil: um estudo de caso no sul do país. DEDiCA. REVISTA DE EDUCAÇÃO E HUMANIDADES, N. 19 , 2021, 333-352. ISSN: 2182-018X. DOI: http://doi.org/10.30827/dreh.vi19.21951 
isso, o aluno se desmotiva e desiste do curso ( $\mathrm{T} 13)$.

Nos dias atuais as atividades estão cada vez mais corridas e pouco tempo sobra para atividades rotineiras, nesse consenso avalio a atuação como professor a distância, se haver de uma forma ou outra a escola de um tempo vago para dedicação como professor isso será possível e trará muitos benefícios em ambas as partes (T17).

O PPC tem grande influências, é ele que nos orienta o ruma a tomar no planejamento de nossas aula, também outros elementos tecnológicos não previsto no projeto que podemos complementar nossas atividade como professor, como exemplo o mundo das coisa em volta da internet, celulares e todas as novas tecnologia disponível, é só saber usar (G2).

Sim, é a ele que recorremos para guiar o trabalho em desenvolvimento. Geralmente é feito reuniões com coordenador de tutoria, coordenador de curso para tratar de assuntos relevantes e juntos encontrarmos um procedimento ou uma intervenção necessária a solução do empasse ou da dificuldade do momento (PF2).

Sim, pois procuro atuar obedecendo o que está disposto no PPP4. Sabemos que a educação não é algo estático, imutável, por isso, procuro evoluir constantemente nesse sentido (PF3).

Inovação com a forma de aprendizagem dos alunos. Provas diferenciadas, aulas dinâmicas (T6).

Sempre por iniciativa dos professores ou coordenadores. Por exemplo, criação de videoconferências para apresentação de trabalhos (T4).

Hoje estou sem classe, mas observo os professores que proporcionas novas experiências inovadora em sua disciplinas, que é muito aceito pelos alunos (G2).

Planejamos elaborar anualmente um encontro entre professores, tutores e os alunos dos polos do curso de Secretaria Escolar, no qual cada cidade polo deve apresentar de modo livre e criativo um trabalho

Pasqualli, Roberta; Carvalho, Marie Jane Soares (2021). Os saberes docentes dos professores da Rede E-TEC Brasil: um estudo de caso no sul do país. DEDiCA. REVISTA DE EDUCAÇÃO E HUMANIDADES, N.19, 2021, 333-352. ISSN: 2182-018X. DOI: http://doi.org/10.30827/dreh.vi19.21951

Práticas

inovadoras em EAD
Projeto

pedagógico dos cursos de EAD 
realizado em uma das disciplinas já ofertadas pelo curso (PF5, G1).

Este prática tem dado certo, pois os alunos interagem durante todo o dia com as mostras de trabalho, palestras, conhecem pessoalmente seus professores e tutores, sem contar a troca de experiências entre os polos. Percebemos que este evento aproxima a todos os envolvidos no processo ensino-aprendizagem e foi aprovado pelos alunos que aguardam por esta troca (PF8).

Como inovações nesse curso por parte de minha disciplina foi a aplicação das provas a distancia, sendo que os alunos podem ficar em suas casas ou ir até o polo para realização das mesmas online, sendo essas corrigidas automaticamente na realização (PF9).

\section{Fonte: As pesquisadoras}

Dos cinco episódios ideográficos apresentados anteriormente foram geradas 14 ideias nucleares: (a) formação didático-pedagógica para o exercício da docência; (b) saberes atitudinais; (c) utilizar linguagem adequada; (d) domínio das Tecnologias da Informação e da Comunicação (TICs); (e) Conhecer a EAD; (f) fragilidades conceituais e técnicas; ( $g$ ) dificuldade com as TICs; (h) currículo desconhecido; protagonismo; (i) não há inovações; (j) a ruptura, com a forma tradicional de ensinar e aprender; (I) generosidade; (m) formação científica específica; (n) conhecer o estudante; e (o) EAD quebra paradigmas.

$\mathrm{Na}$ busca pela redução fenomenológica, na análise nomotética, as falas dos participantes foram encaminhadas em direção às generalidades, ou seja, ao conteúdo de características básicas compreendidas nas formas de manifestação do fenômeno, passíveis de interpretação. Desse trabalho analítico, as ideias nucleares, observadas a partir das unidades significado que as constituíram, confluíram, cada uma a seu modo, para a elaboração de duas categorias: saberes didático-pedagógicos e saberes técnico- científicos. Em um segundo movimento de redução, essas duas categorias transformaram-se em uma grande categoria aberta

Pasqualli, Roberta; Carvalho, Marie Jane Soares (2021). Os saberes docentes dos professores da Rede E-TEC Brasil: um estudo de caso no sul do país. DEDiCA. REVISTA DE EDUCAÇÃO E HUMANIDADES, N.19, 2021, 333-352. ISSN:

http://doi.org/10.30827/dreh.vi19.21951

2182-018X.

DOI: 
chamada saberes da profissionalização.

Considera-se que os saberes da profissionalização docente são fruto de uma formação inicial e continuada consciente, ética, crítica e pautada em uma trajetória que reflete continuamente sobre o seu processo de formação, sobre o seu espaço de trabalho e sobre a mundo que deseja para si e para os outros e estes saberes são discutidos na sequência deste artigo.

\section{Discussões}

As pesquisas referentes aos processos de constituição dos saberes docentes na EPT na modalidade de EAD são alvos de tímidos estudos no âmbito das Ciências da Educação. Os poucos estudos existentes, apresentam as fragilidades da modalidade de EAD frente aos desafios da formação para a educação profissional e indicam que as práticas docentes, em suas diferentes singularidades, demandam novos olhares, fruto das particularidades do conhecimento e das habilidades profissionais que demarcam este nível de formação (Pasqualli, Vieira \& Vieira, 2015).

Peterossi (1994) reflete que, historicamente, a educação profissional esteve desarticulada da formação regular e, com isso, as instituições de formação deste nível desenvolveram uma mentalidade claramente empresarial, incorporando em sua estrutura e organização procedimentos eminentemente utilitários.

Em 1909, Nilo Peçanha, então Presidente da República, criou a Rede Federal de Educação Profissional e Tecnológica, destacando a necessidade de oferecer preparo técnico e intelectual que lhes permitisse garantir os meios de sobrevivência, assim como levá-los a adquirir hábitos de trabalho contínuo que os afastassem do ócio, do crime e do vício (Brasil, 1909).

Com a redução da educação profissional ao 'saber-fazer', observa-se que até hoje acredita-se que para ser professor de disciplinas ou áreas tecnológicas, mais vale o conhecimento dos conteúdos que se vai lecionar que propriamente a formação pedagógica (Macieira, 2009). Ainda, para Oliveira \& Silva (2006), o professor de educação profissional não é considerado um profissional da educação. Ele é um profissional de uma área

Pasqualli, Roberta; Carvalho, Marie Jane Soares (2021). Os saberes docentes dos professores da Rede E-TEC Brasil: um estudo de caso no sul do país. DEDiCA. REVISTA DE EDUCAÇÃO E HUMANIDADES, N.19, 2021, 333-352. ISSN:

http://doi.org/10.30827/dreh.vi19.21951

2182-018X.

DOI: 
específica que também leciona. As autoras apontam como obstáculo ao reconhecimento da docência como profissão que: "[...] as áreas técnicas não contam com um corpo de estudos razoavelmente denso que, tendo por objetivos a pesquisa da prática pedagógica dos seus professores e da prática profissional, no mercado de trabalho, auxilie o entendimento epistemológico do ensino nessas áreas e a pedagogização do saber a elas correspondente" (Oliveira \& Silva, 2010, p. 470).

As mesmas autoras, seguem refletindo sobre o fato de que, atualmente, no Brasil, não existe um marco regulatório que dê conta da formação de professores para a educação profissional e tecnológica, tampouco para a EAD e estas vem sendo tratadas como algo especial, emergencial, sem integralidade própria e viabilizando propostas de formação aligeirada e superficial (Oliveira \& Silva, 2005). Tardif (2002, p. 36) define saber docente como "um saber plural, formado pelo amálgama, mais ou menos coerente, de saberes oriundos da formação profissional e de saberes disciplinares, curriculares e experienciais." O autor atribui ao saber docente um sentido amplo, que engloba os conhecimentos, as competências, as habilidades (ou aptidões) e as atitudes dos docentes, tudo aquilo que é chamado de saber, de saber-fazer e de saber-ser.

Tardif (2002, p. 120), ainda destaca que "a tarefa do professor consiste, grosso modo, em transformar a matéria que ensina para que os alunos possam compreendê-la e assimilá-la". Essa 'transformação', na educação profissional e tecnológica na modalidade de EAD é tarefa complexa, já requer um olhar para a formação do ser humano integral, não utilitário, mas de preparação para o mundo do trabalho sem, necessariamente, a presença do estudante em sala de aula.

Para Charlot (2018, p. 62) "não é o saber que é prático, mas, sim, o uso dele, em uma relação prática com o mundo". Essa perspectiva permite deduzir que a prática pode ser também uma forma de saber e, na mesma lógica, pode-se inferir que os saberes práticos dos professores são mobilizados em suas práticas de ensino, com base em sua atuação profissional, durante a construção da professoralidade.

Pasqualli, Roberta; Carvalho, Marie Jane Soares (2021). Os saberes docentes dos professores da Rede E-TEC Brasil: um estudo de caso no sul do país. DEDiCA. REVISTA DE EDUCAÇÃO E HUMANIDADES, N.19, 2021, 333-352. ISSN: 2182-018X. DOI: http://doi.org/10.30827/dreh.vi19.21951 
Kuenzer (2008) reforça a ideia de que existe uma nova concepção de educação profissional que transita da hegemonia do paradigma taylorista/fordista para uma nova concepção de trabalho fundado na flexibilização. Esse novo regime de trabalho demanda uma nova concepção de formação de professores para a educação profissional e tecnológica. A mesma autora, ao referir-se ao professor da educação profissional destaca a necessidade de "estudar o trabalho na dimensão ontológica, como constituinte do ser social capitalista; há de estudar como as bases materiais cimentadas pela ideologia conformam subjetividade que não se reconhecem como excluídas" (Kuenzer, 2008, p. 33). Aponta ainda que um bom engenheiro mecânico não necessariamente é um bom professor e as interfaces entre o conhecimento científico e escolar devem ser observadas com cuidado durante a transposição didática.

Com essas novas exigências, não basta apenas saber na prática e é impossível separar do trabalho docente o desenvolvimento de saberes cognitivos complexos, o raciocínio lógico-formal, as capacidades comunicativas e a criatividade, entre outros. Sendo assim, observa-se que os saberes estão presentes no cotidiano das ações docentes e obrigam todos os professores a dialogar com o sentido de que não se pode ser neutro quando se fala em educação.

O conhecimento do professor não é meramente acadêmico, racional, feito de fatos, noções e teorias, como também não é um conhecimento feito só de experiência. É um saber que consiste em gerir a informação disponível e adequá-la estrategicamente ao contexto da situação formativa em que, em cada instante, se situa sem perder de vista os objetivos traçados. É um saber agir em situação. Mas não se fique com uma ideia pragmático-funcionalista do papel do professor na sociedade, porque o professor tem de ser um homem ou uma mulher de cultura, ser pensante e crítico, com responsabilidades sociais no nível de construção e do desenvolvimento da sociedade (Alarcão, 1998, p.104).

No que diz respeito às discussões acerca da formação de professores para a modalidade de EAD, Litwin (2001) com o olhar em Shulman (1995), há mais de 15 anos já destacava, como princípios de ação e reflexão, o conhecimento do conteúdo,

Pasqualli, Roberta; Carvalho, Marie Jane Soares (2021). Os saberes docentes dos professores da Rede E-TEC Brasil: um estudo de caso no sul do país. DEDiCA. REVISTA DE EDUCAÇÃO E HUMANIDADES, N.19, 2021, 333-352. ISSN: 2182-018X. DOI: http://doi.org/10.30827/dreh.vi19.21951 
conhecimento pedagógico de tipo real, especialmente no que diz respeito às estratégias e à organização da classe, conhecimento curricular, conhecimento pedagógico acerca do conteúdo, conhecimento sobre os contextos educacionais e conhecimento das finalidades, dos propósitos e dos valores educativos e de suas raízes históricas e filosóficas.

Souza (2004, p. 3), aponta para a reflexão acerca de algumas diferenças entre as modalidades de EAD e presencial, as relações estabelecidas e o direcionamento do professor sobre o processo pedagógico é mais evidente, ou seja, as relações de poder são mais diretas e ele dispõe de mecanismos de organização e controle já conhecidos, experienciados. Ao se deparar como educador na EAD, esses mecanismos não funcionam da mesma forma: o olhar repreensivo ou mesmo complacente e compreensivo, o gesto brusco ou delicado e o acompanhamento, in loco, do desempenho do aluno, representam algumas atitudes que têm de ser reorganizadas e transformadas (Souza, 2004, p. 3).

Sendo assim, defende-se que os saberes mobilizados pelos professores da EPT na modalidade de EAD não podem ser percebidos de forma isolada, mas sim, como um conjunto das reflexões e das práticas diárias. É neste contexto que as discussões acerca dos saberes docentes para a EPT na modalidade de EAD se constituem, se fundem e se con(fundem) com os saberes docentes da educação presencial.

Observou-se, durante a pesquisa, que os saberes docentes, defendidos por Tardif (2002) são reconhecidos e extrapolados; para ser professor da EPT na modalidade de EAD, faz-se necessário saberes outros da educação presencial. Saberes diferenciados requerem reflexões e práticas diferenciadas, já que "uma aula interessante é uma aula na qual se estabelece uma forma específica, uma relação com o mundo, uma relação consigo mesmo e uma relação com o outro" (Charlot, 2018, p. 73).

A partir das discussões apresentadas anteriormente, destacam-se, na sequência, os saberes oriundos da profissionalização docente considerados, a partir desta pesquisa, como fundamentais para a docência na EPT na modalidade de EAD: (a) saberes dos contextos dos estudantes; (b) saberes da

Pasqualli, Roberta; Carvalho, Marie Jane Soares (2021). Os saberes docentes dos professores da Rede E-TEC Brasil: um estudo de caso no sul do país. DEDiCA. REVISTA DE EDUCAÇÃO E HUMANIDADES, N․19, 2021, 333-352. ISSN: 2182-018X. DOI: http://doi.org/10.30827/dreh.vi19.21951 
linguagem; (c) saberes dos aparatos tecnológicos; (d) saberes da generosidade; (e) saberes do mundo do trabalho e, (f) saberes da formação humana não utilitarista (ser humano integral).

Nesta direção, defende-se que sejam elaborados processos de profissionalização docente - inicial e continuado - para educação profissional na modalidade de EAD que podem ser constituídos a partir das experiências vivenciadas na prática diária, configurandose como um processo permanente de formação já que a construção e a re(construção) da docência muitas vezes se dá no próprio percurso da vida profissional.

\section{Conclusões}

O movimento efetuado durante as análises ideográfica e nomotética desvelou articulações que construíram a categoria aberta 'saberes da profissionalização docente'. Esta categoria revela as faces do fenômeno 'saberes docentes da EPT na modalidade de EAD', visualizadas e compreendidas no contexto dos cursos da Rede E-Tec Brasil no IFFAR.

Durante o processo de pesquisa de campo, o fenômeno 'saberes-docentes-da-EPT-na-modalidade-de-EAD' foi tratado de forma a trazer à luz os saberes docentes mobilizados pelos professores, as possibilidades sinalizadas por esses saberes e os tensionamentos apontados.

Demarcado o contexto teórico em que este estudo se apresentou, partiu-se da compreensão do saber docente, como saber social, que se manifesta nas relações complexas entre os professores e os estudantes.

Foram identificadas algumas contradições entre o que se escreve, o que se diz e o que se faz. Na análise ideográfica, pôdese perceber fragilidades teóricas no que diz respeito a compreensão da EAD e sua relação com o mundo do trabalho. Também ficou claro que a integração entre os pares educacionais da EPT poderia ser maior e isto contribuiria para a qualificação do curso oferecido.

A preocupação relacionada às dimensões ontológica, histórica e intelectual não apareceu como saber necessário a docência e isso causa um certo estranhamento, já que é

Pasqualli, Roberta; Carvalho, Marie Jane Soares (2021). Os saberes docentes dos professores da Rede E-TEC Brasil: um estudo de caso no sul do país. DEDiCA. REVISTA DE EDUCAÇÃO E HUMANIDADES, N.19, 2021, 333-352. ISSN:

http://doi.org/10.30827/dreh.vi19.21951

2182-018X.

DOI: 
fundamental romper com a dualidade estrutural existente na educação como um todo e refletida na EPT na modalidade de EAD.

Apresenta-se, como saberes fundamentais, a atividade docente na educação profissional e tecnológica a distância, os saberes da profissionalização docente e entre eles, destaca-se os saberes dos contextos dos estudantes, os saberes da linguagem, os saberes da utilização dos aparatos tecnológicos, os saberes da generosidade, os saberes do mundo do trabalho e, os saberes da formação humana não utilitarista.

Como conclusões, e respondendo à pergunta principal da pesquisa, compreendemos que os saberes docentes relacionam-se necessariamente à profissionalização docente. A profissão docente não é neutra, como afirma Cunha (2005) e, se não neutra, precisa estar munida de conceitos e práticas voltados para a formação de um sujeito capaz de interagir e transformar um mundo minado de ideologias e valores.

Ao final, defende-se, a partir da análise dos dados oriundos da análise ideográfica e nomotética a importância de que os saberes docentes são oriundos da profissionalização docente, fruto de uma formação inicial e continuada consciente, ética, crítica e pautada em uma trajetória que reflita continuamente sobre o seu processo de formação, sobre o seu espaço de trabalho e sobre a mundo que deseja para si e para os outros.

\section{Referências}

Alarcão, I. (1998). Formação continuada como instrumento de formação docente. In: I. Veiga (org.), Caminhos da profissionalização do magistério (pp. 99-122). Campinas, São Paulo (Brasil): Papirus.

Bicudo, M. A. V. (1999). A contribuição da fenomenologia à educação. In: Bicudo, M. A. V.; Cappelletti, I. F. (Orgs.), Fenomenologia: uma visão abrangente da educação (pp. 11-51). São Paulo (Brasil): Olho d'Água.

Brasil. (1909). Decreto $\quad n^{0} \quad 7566$. http://portal.mec.gov.br/setec/arquivos/pdf3/decreto_7566_1909.pdf

Brasil. (2008). Lei $\quad n^{\circ} \quad 11.892$. http://www.planalto.gov.br/ccivil_03/_Ato20072010/2008/Lei/L11892.htm

Pasqualli, Roberta; Carvalho, Marie Jane Soares (2021). Os saberes docentes dos professores da Rede E-TEC Brasil: um estudo de caso no sul do país. DEDiCA. REVISTA DE EDUCAÇÃO E HUMANIDADES, N.19, 2021, 333-352. ISSN: 2182-018X. DOI: http://doi.org/10.30827/dreh.vi19.21951 
Brasil. (2011). Decreto $n^{\circ}$ 7.589. http://www.planalto.gov.br/ccivil 03/_Ato2011-2014/2011/Decreto/D7589.htm

Charlot, B. (2018). Da relação com o saber. Porto Alegre (Brasil): Artes Médicas.

Cunha, M. I. (2005). O professor universitário na transição de paradigmas. Araraquara, São Paulo (Brasil): JM Editora.

Goldenberg, M. (1997). A arte de pesquisar: Como fazer pesquisa qualitativa em ciências sociais. Rio de Janeiro (Brasil): Record.

Kuenzer, A. (2008). Formação de professores para a educação profissional e tecnológica: Perspectivas históricas e desafios contemporâneos. In: INEP. Formação de professores para educação profissional e tecnológica. Brasília, 26, 27 e 28 de setembro de 2006. Brasília (Brasil): Instituto Nacional de Estudos e Pesquisas Educacionais Anísio Teixeira.

Litwin, E. (2001). Educação a distância: Temas para o debate de uma nova agenda educativa. Porto Alegre (Brasil): Artmed.

Macieira, D. de S. (2009). Limites e possibilidades da formação inicial de professores da educação profissional através do programa especial de formação pedagógica de docentes, segundo as representações de seus egressos. Dissertação (Mestrado em Tecnologia) - Centro Federal de Educação Tecnológica de Minas Gerais, Belo Horizonte (Brasil).

Oliveira, F. C. P.; Silva, C. S. da (2010). Ensino médio integrado à profissionalização: Os desafios para a formação docente. In: II Seminário Nacional de Educação Profissional e Tecnológica - SENEPT. Minas Gerais (Brasil): CEFET-MG. http://www.senept.cefetmg.br/galerias/Anais_2010/ Artigos/GT8/FORMACAO_PEDAGOGICA.pdf

Pacheco, E. (2010). Os Institutos Federais: Uma revolução na educação profissional e tecnológica, 2010. http://portal.mec. gov.br/index.php? option=com_content\&view=article\&id=14428

Pasqualli, R.; Carvalho, M. J. S. (2016). Os saberes docentes nos cursos de licenciatura a distância em ciências naturais e matemática nos institutos federais do Brasil. Ciência \& Educação (Bauru), 22(2), 523-540. https://www.scielo.br/scielo.php?pid=S1516-73132016000200523\& script=sci_abstract\&tIng=pt

Pasqualli, R.; Vieira, M. M.; Vieira, J. A. (2015). Formação de professores para a educação profissional e tecnológica à distância da rede federal de educação brasileira: Análise das produções acadêmicas. Revista Brasileira da Educação Profissional e Tecnológica, 9(2), 22-31. http://www2.ifrn.edu.br/ojs/index.php/RBEPT/article/view/3558

Peterossi, H. G. (1994). Formação do professor para o ensino técnico. São Paulo (Brasil): Edições Loyola.

Pasqualli, Roberta; Carvalho, Marie Jane Soares (2021). Os saberes docentes dos professores da Rede E-TEC Brasil: um estudo de caso no sul do país. DEDICA. REVISTA DE EDUCAÇÃO E HUMANIDADES, N․19, 2021, 333-352. ISSN: 2182-018X. DOI: http://doi.org/10.30827/dreh.vi19.21951 
Shulman L. S. (2005). Conocimiento y enseñanza: fundamentos de la nueva reforma. Profesorado. Revista de Currículum y Formación de Profesorado. 9(2), 1-30.

Souza, A. R. B. de (2004). Saberes docentes na educação a distância - análises e prospecções.

http://www.abed.org.br/congresso2004/por/htm/027-TC-A2.htm

Tardif, M. (2002). Saberes docentes e formação profissional Petrópolis (Brasil): Vozes.

\section{Para saber mais sobre as autoras...}

\section{Roberta Pasqualli}

Graduação em Ciência da Computação pela Universidade do Oeste de Santa Catarina (1999), Especialização em Informática pela Universidade Federal de Santa Catarina (2001), Especialização em Teorias e Metodologias da Educação pela UNOCHAPECÓ (2005), Especialização em Docência no Ensino Superior pela UNOCHAPECÓ (2008), Mestrado em Ciências da Computação pela Universidade Federal de Santa Catarina (2002) e Doutorado em Educação pela Universidade Federal do Rio Grande do Sul (2013). É professora do Instituto Federal de Educação, Ciência e Tecnologia de Santa Catarina - Câmpus Chapecó. Tem experiência na área de Educação, com ênfase em Inovações Pedagógicas, Saberes Docentes e Currículo Integrado. É Pós-Doutora em Educação pela Universidade Federal do Rio Grande do Sul onde estudou os saberes docentes dos professores do Sistema Rede E-TEC Brasil. É professora permanente e Coordenadora do Programa de Pós-Graduação - Mestrado Profissional em Educação Profissional e Tecnológica - PROFEPT - IA - IFSC. Avaliadora BASis do Instituto Nacional de Estudos e Pesquisas Educacionais Anísio Teixeira, Brasil.

\section{Marie Jane Carvalho}

Pós-doutorado-UNED/Madrid. (2012).Doutora em Educação pela Universidade Federal do Rio Grande do Sul (1999). Estágio de Doutorado na University of Toronto (1997). Mestre em Educação (1990). Graduação em Pedagogia (1982). Professora Titular do Departamento de Ensino e Currículo/Faculdade de Educação/ Universidade Federal do Rio Grande do Sul. Docente no Programa de Pós-graduação em Informática na Educação (PPGIE).Trabalha com a linha de pesquisa em: Ambientes Informatizados e Currículo a Distância, Arquiteturas Pedagógicas, Análise de Redes Sociais,

Pasqualli, Roberta; Carvalho, Marie Jane Soares (2021). Os saberes docentes dos professores da Rede E-TEC Brasil: um estudo de caso no sul do país. DEDICA. REVISTA DE EDUCAÇÃO E HUMANIDADES, N․19, 2021, 333-352. ISSN: 2182-018X. DOI: http://doi.org/10.30827/dreh.vi19.21951 
Formação de Professores. É consultora na área de tecnologias digitais e formação de professores.

\section{Como citar este artigo...}

Pasqualli, Roberta; Carvalho, Marie Jane Soares (2021). Os saberes docentes dos professores da Rede E-TEC Brasil: um estudo de caso no sul do país. DEDiCA. REVISTA DE EDUCAÇÃO E HUMANIDADES, 19, 333352.

DOI: http://doi.org/10.30827/dreh.vi19.21951

${ }_{1}^{1}$ Análise ideográfica tem por objetivo trabalhar com o destaque das ideias individuais expostas no discurso e apresentadas por textos descritivos. Já a análise nomotética parte das ideias destacadas nos discursos da análise ideográfica e segue buscando características gerais ou da essência do fenômeno, evidenciadas por categorias que indicam grandes regiões de generalização e que, neste movimento, abrem-se para a compreensão e interpretação do fenômeno que é sempre situado no mundo da vida dos sujeitos. (Pasqualli \& Carvalho, 2016).

2 "AVA" é a abreviatura de Ambiente Virtual de Aprendizagem.

3 Hannah Arendt foi uma filósofa e teórica política contemporânea (1906 - 1975). Judia nascida na Alemanha, Arendt vivenciou a perseguição nazista e tornou-se pesquisadora sobre o fenômeno do totalitarismo. Suas principais obras são "As Origens do Totalitarismo", "Eichmann em Jerusalém", "Entre o Passado e o futuro" e "A Condição Humana".

4 "PPP" é a abreviatura de Projeto Político Pedagógico.

Pasqualli, Roberta; Carvalho, Marie Jane Soares (2021). Os saberes docentes dos professores da Rede E-TEC Brasil: um estudo de caso no sul do país. DEDiCA. REVISTA DE EDUCAÇÃO E HUMANIDADES, N. 19 , 2021, 333-352. ISSN:

http://doi.org/10.30827/dreh.vi19.21951

2182-018X.

DOI: 